\title{
The existing problem, countermeasure and development trend for collection and recycling system of end-of-life vehicles in China *
}

\author{
Yang Yang ${ }^{\dagger}$ and Yan-Ping Yang \\ State Key Laboratory of Advanced Design and \\ Manufacturing for Vehicle Body, \\ Changsha, 410082, China \\ E-mail:657842536@qq.com
}

\begin{abstract}
In the paper, the existing problem for its different parts of the collection system on ELV (end-of-life vehicle) are investigated deeply in China. Considering the national conditions, specific measures are taken to improve the automobile collection system, and a new system of the ELV recycling is provided. This investigation will provide some useful advices and be a reference to carry smoothly out the ELV project and the implementation of international standards on the automobile collection and recycling system in China.

Keywords: Automobile Industry; End-of-Life Vehicles; Collection and Recycling System; Disassembling; Countermeasure and Development.
\end{abstract}

\section{Introduction}

Growing concern for environmental problems has led to a range of productoriented policies that after various industrial sectors. Automobile manufacturing has increased in the last 20 years in China, with the vigorous development the automobile industry, ELV recycling industry also ushers in a period of new and old alternate. Hence, a rational ELV recycling system is needed in China.

Abundant investigations around this problem both in and abroad can be found in literatures. For ELV recycling industry in China, there are lots of investigations on ELV recycling system[1-6]. By weighted average method according to statistical data, a forecast on the amount of end-of-life vehicles in province and municipalities was presented[7]. By following the EU ELV directive, some impetus for ELV recycling industry developments and insight into current thinking about ELV recycling as well as vehicle recovery activities were provided by Chen[8]. An automobile products recoverability target had been established by Chen[9] and would be incorporated into an automobile products authentication management system. Base on reviewing the ELV policy,

* This work is supported by the National Natural Science Foundation of China (71173072). 
law, and administration system, the challenges and opportunities of ELV recycling and the state of the art of remanufacturing of ELVs were analyzed[10]. Based on the reclamation strategy, a hierarchy disassembly model and established an economic evaluation model for recycling of end-of-life vehicle to evaluate reclamation profit quantitatively was presented[11]. By carrying out a disassembly experiment of an end-of-life engine, a model of the end-of-life recycling, and improved the dismantling efficiency and the recycling rate was presented[1]. By analyzing the resources input characteristics at different development stages, some problems before remanufacturing were presented[12], during remanufacturing and after remanufacturing, and then it pointed out several barriers, such as restrictive policies and regulations, consumer acceptance, scarcity of technologies, etc. By analyzing China's ELV recycling industry to facilitate its development, strategies and perspectives were proposed by Wang and Chen[1] to China government to improve the policies and regulation for ELV recycling industry. Zhao and Chen[13]made a comparison of the present situation of scrap automobiles between Japan and China, and tried to find an appropriate way for China to deal with the problem of scrap automobiles. By comparing with the developed countries, effective measures to meet the aims stipulated in the law were put forward[14] based on the current practical ELV market. By means of a comparative analysis of ELV recycling laws and advance dismantling experiments, Che et al.[15] presented and did future scenario analysis about end-of-life vehicle recycling and international cooperation between Japan, China and Korea.

Currently, most of the other countries addressing the improvement of ELV recycling processes are industrialized countries. For ELV recycling industry in other countries, there are also lots of investigations[16-21]. By exploring the limits of recycling on a fundamental basis, the fundamental limits for the recycling of end-of-life vehicles were researched[22]. Legislation by the European Commission and the fast-growing consumption of metals had created an uneven playing field and new markets, which influenced the technological developments in the United States and the European Union, the development of vehicle recycling in Europe was analyzed[23]. Based on five anticipated changes that could result from the ELV Directive, the impact of the ELV Directive on green innovation and vehicle recovery was assessed[24]. Based on a model developed to simulate ELV processing infrastructures, and shredding data were taken from full-scale experiments, Ferrao et al.[25] presented the strategies for meeting EU end-of-life vehicle reuse/recovery targets. Based on the producer responsibility principle, Mazzanti and Zoboli[26] addressed the mechanisms by which specific economic instruments would affect innovation when environmental policy had impact on very complex industrial subsystems. A 
closed-loop supply chain for the collection of end-of-life vehicle was built by Cruz-Rivera and Ertel [27], and they designed a reverse logistics network for the collection of end-of-life vehicles in Mexico. According to the results obtained in their work, Santini et al.[28] focused on the calculation of the effective Italian ELV recycling rate, which resulted equal to $80.8 \%$, and auto shredder residue characterization.

From those many investigations, the current situations and existing problems of ELV recycling in China can be seen, and the ELV recycling system in other countries can be used as references to build the ELV recycling system in China. In order to realize sustainable development strategy and build a society of resource conserving and friendly environment, high utilization of ELV and construction of green ELV recycling system are consistent with our real national conditions and environment protection requirements.

\section{The Current Situation and Existing Problems of the ELV Recycling System in China}

\subsection{The current ELV recycling process in China}

According to the related statistical results, by the year 2009, there had been more than one thousand companies which have the abilities to disassemble and recycle ELVs[29], more than 50 thousand practitioners related to this field and more than 2 million ELVs can be recycled in every year. By investigating the most present regular ELV recycling companies in China, the following process can be achieved[30]. The flow chart of the existing ELV recycling system in China is shown in Figure 1.

\subsection{The current situation on the existing ELVs recycling system in China}

As the fast development of transportation in both cities and countries, the number of automobiles ownership rises rapidly, and this number exceeds 100 million in 2010. Therefore, more than 7 million automobiles have to be scrapped every year for the scrap rate is $7 \%$. According to the ELV recycling management regulations published as the 307th Directive of the State Council of China, units or individuals who have no qualifications of retrieving and dismantling ELVs must not do this work[31]. Moreover, in recent years, many relevant policies have been introduced to support this work in China, such as the new-for-old policy, technical specifications for ELV recycling enterprises and enterprise reform and development technology[32]. Even so, the recovery rate of ELVs in China is just about $25 \%[33,30]$. Based on the statistics by the relevant departments, to 2015, there will be 8.31 million ELVs needing to be recycled in 
China. Thus, the work of collection and recycling should be devoted to ensure the smoothly implementation of ELV recycling program.

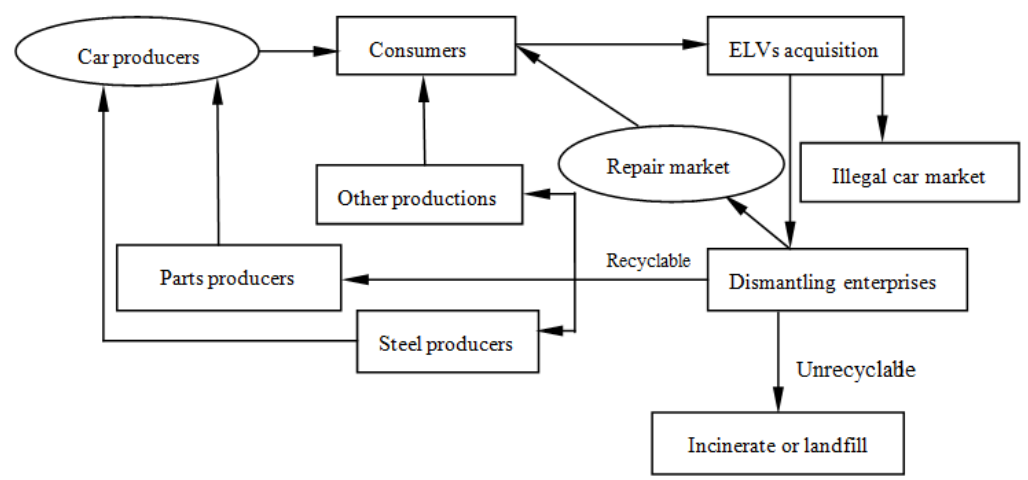

Fig. 1. The flow chart of the existing ELV recycling system in China

The ELV recycling industry has built its general frame under the advocating of the development of circular economy and the construction of saving type society. However, from the current situation of ELV recycling industry in China, many problems are needed to be solved, such as the low abilities of dismantling, the simple and crude equipment, the limited recycling scale, the loose management, the problem of secondary pollution, mismatch between the recycling laws and national conditions and various potential security risks[34]. It is not difficult to find that our scrap vehicle recycling system needs to be further solved for some problems.

\subsection{The existing problems in current ELV recycling system in China}

The problems in current ELV recycling system in China call for serious investigation and deep governance. The loopholes happened in almost every link of the recycling process, from inspection and registration, pretreatment, automobiles storage, dismantling and management of ELVs; the pitfalls occurred from recycling to supervision. According to the abundant investigation, the existing main problems are found in the following aspects.

\subsubsection{The low recovery rate of ELVS}

In many other countries, recycling of ELVs is not a problem that most people are willing to send ELVs to the recycle market, while in China, some ELVs are flowing into illegal car market, some ELVs are still running on roads and other ELVs are sent to the recycle market. From relevant statistical data, it can be seen that there are more than 90 million ELVs in China by the end of 2010, 3.64 million ELVs are written off, but less than 1.48 million ELVs are recycled[14]. 
In recent years, the number of really recycled and dismantled ELVs keeps 700 thousand every year, and this number of ELVs is just yet half of the one which is recorded on the cancellation of registration list of the public security traffic administration and it is becoming smaller year by year[35].

\subsubsection{Simple and old equipment, unsound management mechanism and low practitioners' diathesis}

For the pursuit of profit, ELVs are illegal collected modification and change some parts through the black market and then flow into the used automobile market, which brings lots of potential security risk. Most of the ELV recycling companies are facing severe funding crisis[14], they are unable to purchase for new equipment and introduce new technology, enterprises remain rely heavily on labor density rather than mechanization, and cause the waste of resource and practitioners. Meanwhile, practitioners in ELV recycling enterprises are too many and most of them have not received formal training, which leads to the low practitioners' diathesis and confused management.

\subsubsection{Ambiguous and imperfection of the policy system}

Recently, laws and policies about ELV recycling are too old to regulate the current ELV recycling and dismantling market. Qualification for ELV recycling enterprise is canceled by About the Cancellation of the First Batch of Administrative Examination and Approval of the State Council's Decision in November, 2002. This makes some local governments misread it as the relaxation of ELV recycling policies. But the truth is that the entry conditions of decree 307 th Directive disagrees the national developments because of its lack of technical regulations of recycling and dismantling and environmental protection standard[33,35]. Environmental Protection Technical Specification for ELV Dismantling (HJ348-2007) enacted in 2007 makes claims about pollution control in the process of retrieving and dismantling ELVs, but demands on the resource saving and safety are not involved. Retrieving and Dismantling Scrapped Automobiles Enterprise Technical Specification published in 2009 is the first our national mandatory standard for ELV retrieving and dismantling industry which is legal and putting into effect. In the environment protection, safety and resource conservation are all taken into consideration while its implementation effect remains to be seen the test of time [36]. 


\subsubsection{Weak consciousness of environment protection and disordered retrieving and dismantling process}

Recycling enterprises lack of equipment for loss prevention and leakage proof on working places, disorderly emissions of liquid wastes and arbitrary accumulation of solid wastes cause environmental pollution directly. Some parts from ELVs retrieving are only simply collected without effective separation, which brings serious loss of high-value materials like aluminum and magnesium. During the process of transferring or dealing with the waste, it will not only cause environmental pollution but also bring risks for society safety without classifying general solid wastes and hazardous wastes. Arbitrary discharging of waste gas, oil and hazardous substance will pollute atmosphere, land, water, etc.

\section{Research Strategies}

In this paper, to solve the existing problems of the ELV recycling system in China, the following research strategies are put forward on the basis of abundant investigations and combining with the reality condition of our country.

\subsection{Severely punish the illegal vehicle market}

The flowing of scrapped vehicles into the illegal vehicle market not only obstacles the healthy development of the ELV recycling industry, but also brings the problem of traffic safety. Various media can be used to introduce the disadvantages of the illegal vehicle market and the legal knowledge of ELV recycling. Moreover, the government should provide the corresponding recycling subsidies to the final consumers according to conditions of the ELVs. In order to standardize the recycling trend of scrapped ELVs, relevant laws and regulations of punishment both buyers and sellers of illegal automobiles should be published. Whether the governance of illegal vehicle market will be succeed or not relates directly to the healthy and smooth development of ELV recycling industry and the safety guarantee of road traffic, and also it is a reflection of the consciousness of law and responsibility of vehicle consumers.

\subsection{Update equipment, adopt advanced technology and improve the qualities of relevant practitioners}

Advanced equipment can save a large number of surplus labors as well as improve the recovery rate of ELVs. The local government departments should increase the intensity of resource integration and support the development of the enterprise. According to our national conditions, advanced equipment and technology from abroad should be introduced, the ELV recovery rate will be increased and labor-saving. Modern enterprise competition in the final analysis 
is the talent competition, ELV recycling enterprise. The production mode of improving production rate relies on the number of practitioners have to be abandoned, and the conditions of low qualities and poor abilities of practitioners and mismatch of abilities with their payment need to be changed by building a strict appraisal and employment mechanism. Only those who are good at advanced technology of work or management may promote the progress of ELV recycling industry.

\subsection{Improve the $E L V$ recycling laws and regulations}

Reset the networks of retrieving, dismantling, recycling and waste treatment combining with the regional layout and interval characteristics of the development of vehicle industry, putting an end to assemble vehicle and punishing the illegal vehicle market from the source. A mature and rational credit mechanism should be built and qualification inspection should be an important basis of supervise recycling enterprises. Vehicle manufacturer need to be asked for using materials and manufacturing technique with less pollution, easy to recycle and convenient to disassemble. Relevant management documents of check and register, preprocess, storage, dismantling and reserve have to be established during the process of the ELV recycling.

\subsection{Strengthen environment protection consciousness and a create harmless recycling system}

In order to protect the environment, realize a sustainable development strategy and improve the recycling utilization of resources, the National Development and Reform Commission of China has drawn up policies of automotive product recycling technology in 2006 with the purpose of promoting the development of the recycling of scrapped automotive product[13]. However, the hysteresis of the legal supervision and strength of the implement of standards leads to the bias of policies in the actual execution. The necessity and operability of the environmental protection should be propagandized to the masses, and establishing environmental standards for vehicle producers, problems and challenges that ELV recycling enterprises in China.

\section{Research on the Process of ELV Recycling}

The flow chart of the existing ELV recycling in China is unable to solve various contradictions in the ELV recycling. Therefore, combining the flow chart of ELVs recycling process in America, Germany, Japan and other countries with the reality of our country, a new flow chart of ELV recycling process is built as shown in Figure 2. 


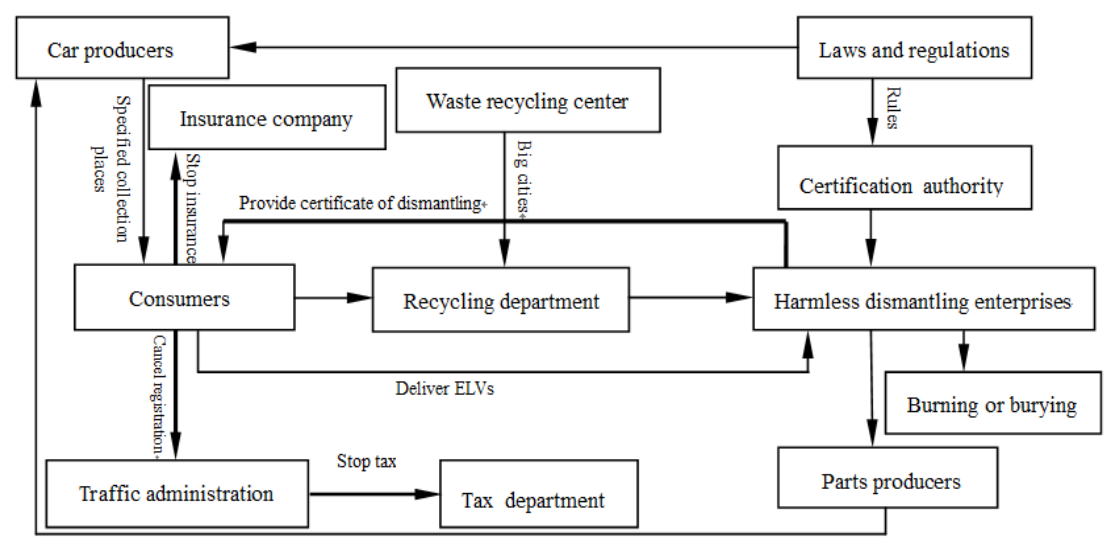

Fig. 2. The flow chart of ELV recycling process.

\section{Conclusions}

In order to realize sustainable development strategy and build a society of resource conserving and friendly environment, high utilization of ELV and construction of green ELV recycling system are consistent with our real national conditions and environment protection requirements. A new flow chart of ELV recycling process is presented. Nowadays, the ELV recycling industry has obtained the support of the government, at the same time, because of the poor equipment, shortage of funds, irregular management standard and low qualities of relevant practitioners of ELV recycling enterprises in China. Some useful advices for the ELV recycling system is given for China government, and the government still needs to invest more capital, establish tax relief policies and provide technical assistance for a better development environment for this industry.

\section{References}

1. J.J. Wang and M. Chen, Recycling of electronic control units from end-oflife vehicles in China, J. JOM63, 42 (2011).

2. W. Xiang and C. Ming, Implementing extended producer responsibility: vehicle remanufacturing in China, J. Journal of Cleaner Production19,680 (2011).

3. Z.Q. Zhou, H.M. Tan and G.H. Dai, Research of flexible dismantling cell for end-of-life vehicle recycling, in 2012 International Conference on Ecology, Waste Recycling, and Environment(ICEWE'2012),( Macao, China, 2012). 
4. S.H. Hu and H. Kurasaka, Projection of end-of-life vehicle population at provincial level of China and analysis on the gap between the future requirements and the current situation of ELV treatment in China, J. Journal of Material Cycles and Waste Management15, 154 (2013).

5. J. Li, K. Yu and P. Gao, Recycling and pollution control of the end of life vehicles in China, J. Journal of Material Cycles and Waste Management16, 31(2014).

6. F. Ni and M. Chen, Studies on pyrolysis and gasification of automobile shredder residue in China,J. Waste Management \& Research32, 980(2014).

7. J.Y. Liu, Q. Qiao and L. Chang, Forecast on the amount of end-of-life vehicles in province and municipalities in China, J. Recyclable Resources \& Circular Economy4, 31(2011).

8. M. Chen, End-of-life vehicle recycling in China: Now and the future, $J$. JOM57, 20(2005).

9. M. Chen, Sustainable recycling of automotive products in China: Technology and regulation, J. JOM58, 23(2006).

10. M. Chen and F. Zhang, End-of-life vehicle recovery in China: consideration and innovation following the EU ELV directive, J. JOM61, 45(2009).

11. Z.F. Liu, S.T. Zhang, S.X. Song and Q.D. Ke, Economic analysis of disassembly and reclamation of end-of-life vehicles, J. Journal of Hefei University of Technology (Natural Science)32, 347(2009).

12. T.Z. Zhang, J.W. Chu, X.P. Wang, X.H. Liu and P.F. Cui, Development pattern and enhancing system of automotive components remanufacturing industry in China, J. Resources Conservation \& Recycling55, 613(2011).

13. Q.H. Zhao and M. Chen, A comparison of ELV recycling system in China and Japan and China's strategies, J. Resources Conservation \& Recycling57, 15(2011).

14. L. Wang and M. Chen, End-of-life vehicle dismantling and recycling enterprises: developing directions in China,J. JOM65, 1015(2013).

15. J. Che, J.S. Yu and R.S. Kevin, End-of-life vehicle recycling and international cooperation between Japan, China and Korea: present and future scenario analysis,J. Journal of Environmental Sciences23, S162(2011).

16. F.D. Hond, The "similarity" and "heterogeneity" theses in studying innovation: evidence from the end-of-life vehicle case,J. Technology Analysis \& Strategic Management10, 529(1998).

17. A. Gesing and R. Wolanski, Recycling light metals from end-of-life vehicle,J. JOM53, 21(2001).

18. N. Kanari, J.L. Pineau and S. Shallari, End-of-life vehicle recycling in the European Union,J. JOM55, 15(2003). 
19. E.J. Daniels, J.A. Carpenter, J.C. Duranceau, M. Fisher, C. Wheeler, G. Winslow, Sustainable end-of-life vehicle recycling: R\&D collaboration between industry and the U.S. DOE,J. JOM56, 28(2004).

20. S.I. Sakai, Y. Noma and A. Kida, End-of-life vehicle recycling and automobile shredder residue management in Japan,J. Journal of Material Cycles and Waste Management9, 151(2007).

21. M. Fuse and S. Kashima, Evaluation method of automobile recycling systems for Asia considering international material cycles: application to Japan and Thailand,J. Journal of Material Cycles and Waste Management10, 153(2008).

22. M.A. Reuter, A. van Schaik, O. Ignatenko and G.J.D. Haanb, Fundamental limits for the recycling of end-of-life vehicles,J. Minerals Engineering19, 433(2006).

23. W.L. Dalmijn and T.P.R. De Jong, The development of vehicle recycling in Europe: sorting, shredding, and separation,J. JOM59, 52(2007).

24. J. Gerrard and M. Kandlikar, Is European end-of-life vehicle legislation living up to expectations? Assessing the impact of the ELV Directive on green innovation and vehicle recovery,J. Journal of Cleaner Production15, 17(2007).

25. P. Ferrao, P. Nazareth and J. Amaral, Strategies for meeting EU end-of-life vehicle reuse / recovery targets,J. Journal of Industrial Ecology10, 77(2006).

26. M. Mazzanti and R. Zoboli, Economic instruments and induced innovation: The European policies on end-of-life vehicles,J. Ecological Economics58, 318(2006).

27. R. Cruz-Rivera and J. Ertel, Reverse logistics network design for the collection of end-of-life vehicles in Mexico,J. European Journal of Operational Research196, 930(2009).

28. A. Santini, L. Morselli, F. Passarini, I. Vassuraa, S.D. Carlob and F. Boninoc, End-of-life vehicles management: Italian material and energy recovery efficiency,J. Waste Management31, 489(2011).

29. G.Y. Hu, Z.P. Du, S.Y. Zhou and Y. Wu, Comparing analysis on collection \& disassembling of scrapped automobiles between China and Japan,J. Logistics Technology (In Chinese)28, 251(2009).

30. Z.Q. Zhou, G.H. Dai and Y.J. Zhang, Investigation of ELV dismantling mode adapting the national conditions of China,J. Journal of Jiangsu Teachers University of Technology(In Chinese)17, 18(2011).

31. L. Wang and M. Chen, Investigation and development strategy research on ELV dismantling and recycling enterprises in China,J. Manufacturing Technology \& Machine Tool(In Chinese) 12, 27(2012). 
32. A.G. Li and G.J. Li, Researches of retrieving and dismantling scrapped automobile enterprises and development strategies in China,J. China Resources Comprehensive Utilization(In Chinese)30, 21(2012).

33. Y. Gong, Development of scrapped automobile recycling industry in China under circulation economy,J. Productivity Research(In Chinese)10, 175(2006).

34. Y.L. Li, The safety management of the scrapped automobiles in the recycling center,J. China Resources Comprehensive Utilization(In Chinese)28, 29(2010).

35. Y. Cai, Current situations and suggestions on scrapped car recycling in China,J. China Resources Comprehensive Utilization(In Chinese)27, 6(2009).

36. H.F. Fang, Y.K. Li and N.J. Zhen, Study on technical specifications for endof-life vehicles recycling-dismantling enterprises,J. Automobile \& Parts(In Chinese)20, 45(2009). 